\title{
Clear Lens Extraction with Foldable Intraocular Lens Implantation in a Case of Isolated Microspherophakia
}

\author{
Chunu Shrestha ${ }^{1}$, Manish Pandey ${ }^{1}$
}

${ }^{1}$ Nepal Eye Hospital, Kathmandu Nepal.

\section{ABSTRACT}

Microspherophakia is an uncommon bilateral eye condition in which there is abnormal laxity of the lens zonules, leading to development of a spherical lens. Microspherophakia without systemic features is a rare presentation. The management of such a case is quite challenging. We report a case of isolated microspherephakia which was managed successfully with clear lens extraction with implantation of a foldable intraocular lens.

Keywords: microspherophakia, phacoemulsification

\section{INTRODUCTION}

Microspherophakia is a rare bilateral condition of the eye characterized by abnormally lax zonules, leading to the development of a small spherical lens. ${ }^{1}$ These small spherical lenses frequently lead to pupillary block with secondary "inverse" angle-closure glaucoma. ${ }^{2,3}$ It has been reported to be associated with many conditions like Weil-Marchesani syndrome, Marfan's syndrome, Alport's syndrome, homocysteinuria, Klinefelter's syndrome, and mandibulofacialdystosis. ${ }^{4,5}$ Ocular complications of microsperophakia include high myopia, pupillary block and secondary angle closure glaucoma, and complications associated with anterior or posterior dislocation of the lens. ${ }^{6,7}$ The management of microspherophakia is quite difficult. We managed a case of isolated mircospherophakia with surgery with good visual outcome.

\section{CASE REPORT}

Eleven years old male adolescent presented in our institute with complaints of blurring of vision in both eyes. The visual acuity at presentation was 2/60 unaided and best corrected visual acuity was $6 / 18 \mathrm{P}$ in both eyes (with correction of $-11.00 /-2.00180^{\circ}$ in right eye and $-11.00 /-2.00180^{\circ}$ in left eye).

Slit lamp examination of anterior segment revealed clear cornea in both eyes. The anterior chamber was shallow in both eyes, depth of which was $2.24 \mathrm{~mm}$ in the right eye and $2.20 \mathrm{~mm}$ in the left eye (normal anterior chamber is 3.46 to $3.80 \mathrm{~mm}$ ) with intraocular pressure of $10 \mathrm{~mm} \mathrm{Hg}$ in both eyes. However on indentation gonioscopy the angles were open (Grade IV). On investigation with dilated pupil, there was a round, spherical, transparent lens present along with thin, stretched zonules (Figures 1 and 2). The thickness of the lens

Correspondence: Chunu Shrestha, Nepal Eye Hospital, Tripureshwor, Kathmandu, Nepal. Email: chunu2o@hotmail.com 


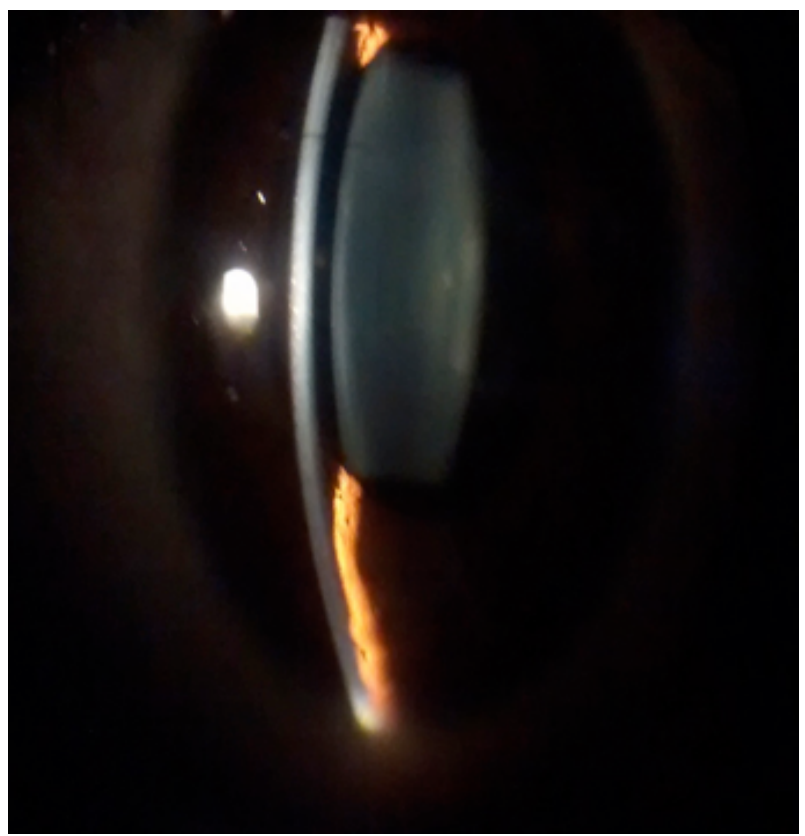

Figure 1: Shallow anterior chamber depth before surgery

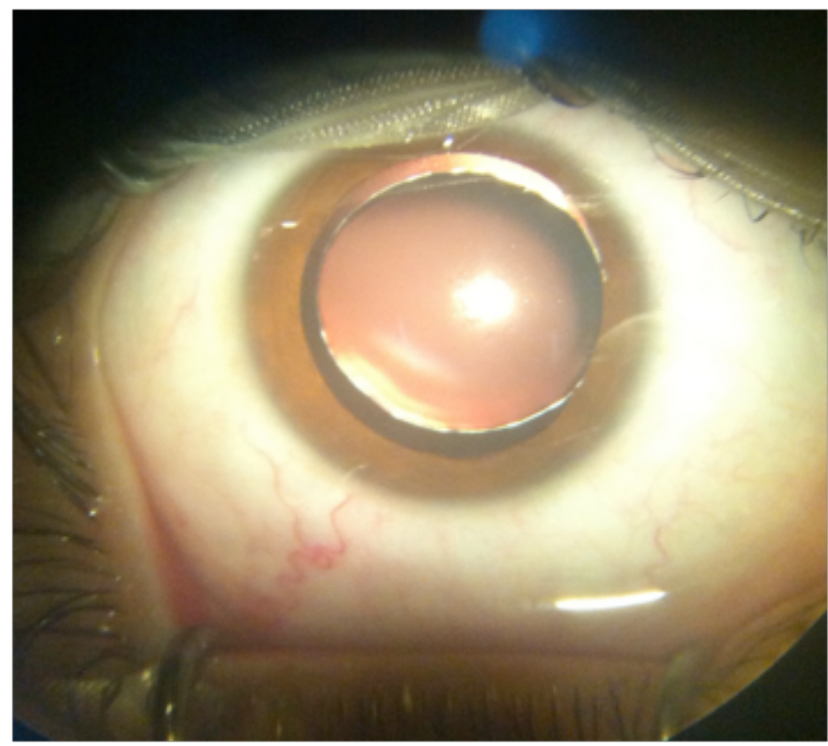

Figure 2: Microspherophakia with visible zonules

was $4.45 \mathrm{~mm}$ in right eye and $4.42 \mathrm{~mm}$ in left eye (normal crystalline lens thickness is 3.30 to $3.96 \mathrm{~mm}$ ). The edges of the lens could be seen and there was no subluxation of lens in both eyes.

The axial length was $22.32 \mathrm{~mm}$ in right eye and $22.47 \mathrm{~mm}$ in left eye. The corneal curvature was within normal limits (K1-7.95,
$\mathrm{K} 2-7.70$ in the right eye and K1-7.94, K2-7.65 in the left eye). Posterior segment was within normal limits.

We planned to opt for surgical correction in the patient. The patient was scheduled for right eye clear lens aspiration with foldable intraocular lens implantation under general anesthesia from the superotemporal route to avoid excess stress on the stretched inferior zonules. A capsulorrhexis was initiated at the center with 23 guage cutter avoiding excess zonular stress and the size of capsulorrhexis was $4 \mathrm{~mm}$. Anterior chamber maintainer was used. Lens aspiration was performed using the simco cannula. Low-flow parameters were used including reduced bottle height and aspiration because of the zonular weakness. Acrylic intraocular lens of +24 Diopter was implanted in the bag.

On the first postoperative day, the IOL was well centered within the bag with minimal anterior chamber reaction. The patient was discharged on topical prednisolone acetate $1 \%$ and Ofloxacin hydrochloride $0.3 \%$. Applanation tonometry was done with IOP of $10 \mathrm{~mm} \mathrm{Hg}$ at $10 \mathrm{am}$. The anterior chamber depth was increased to $3.0 \mathrm{~mm}$ (Fig 3). At the end of 4 week, the best corrected visual acuity was $6 / 9$ with a refractive correction of -0.50 $180^{\circ}$.

The left eye was scheduled for surgery after 1 month and had a similar uneventful course. At the end of 4 week, the best corrected visual acuity was $6 / 9$ with a refractive correction of $-0.50 /-0.75165^{\circ}$ and the anterior chamber depth was $3 \mathrm{~mm}$. The patient was also prescribed reading glasses with which the vision was N6. 


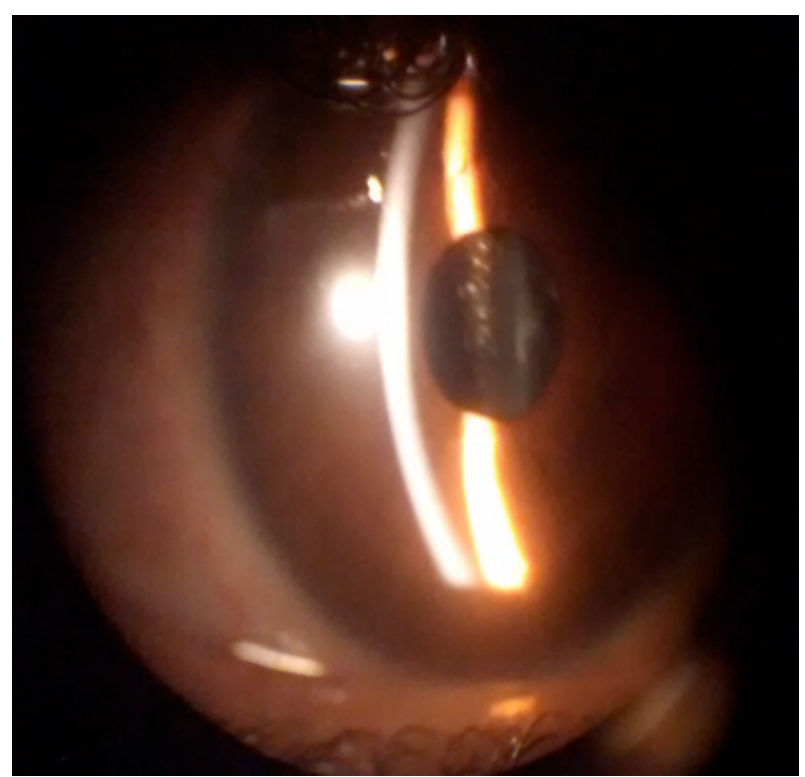

Figure 3: Anterior chamber depth after surgery

\section{DISCUSSION}

Microspherophakia is a rare condition that may occur as an isolated defect or associated with systemic anomalies. ${ }^{1}$ Its association with Weill-Marchesani syndrome and Marfan's syndrome is well documented. ${ }^{2}, 3$ Less commonly, it has been reported in other inherited and developmental disorders including hyperlysinaemia, Alport's syndrome, Lowe's syndrome, Peter's anomaly, Klinefelter's syndrome, mandibulofacial dysostosis, cri-du-chat syndrome, as well as rhizomelic form of schondrodysplasia punctata. $^{4,5}$ Our patient had no features suggestive of any of these conditions.

The cause of microspherophakia is unknown. It has been suggested that it is due to arrest of development of the secondary lens fibres or the insertion of abnormally thin secondary fibres. Both may be secondary to a nutritional deficiency from defects in the tunica vasculosa lentis and both may occur at the fifth to sixth month of embryonic life as the lens is normally spherical at this stage. Cataract surgery in such cases is difficult as the lens is luxated. The options are a capsular tension ring (CTR) and iris hooks. The CTR would be helpful with such weak zonules, but a special small, modified CTR would be needed and was not available.

We believe that clear lens aspiration with IOL implantation should be considered in patients with microspherophakia to deal with high lenticular myopia. In our case, after clear lens extraction with intraocular lens implantation, the best corrected visual acuity at the end of 4 week was $6 / 9$ with a refractive correction of $-0.50180^{\circ}$ in right eye and $-0.50 /-0.75165^{\circ}$ in left eye as compared to the power of $-11.00 /-2.00180^{\circ}$ in both eyes preoperatively.

Lenticular myopia can be disabling in terms of quality of life of the patient with microspherophakia. Clear lens extraction with implantation of a foldable intraocular lens in a patient with microspherophakia helps in the correction of high myopia with good visual recovery.

\section{REFERENCES}

1. Berger BB, Emery JM, Brown NV, et al. The lens, cataract,and its management. In: Peyman GA, Sanders DR, Goldberg MF, eds, Principles and Practices of Ophthalmology.Philadelphia, PA, WB Saunders, 1980; 506-507.

2. Probert LA. Spherophakia with brachydactyly: Comparison with Marfan's syndrome. A m J Ophthalmol 1953;36:1571-1574. 
3. Willi M, Kut L, Cotlier E. Pupillary-block glaucoma in the Marchesani syndrome. Arch Ophthalmol 1973; 90:504-508.

4 Willoughby CE, Wishart PK. Lensectomy in the management of glaucoma in spherophakia. J Cataract Refract Surg 2002; 28(6): 1061-1064.

5 Nelson LB, Maumenee IH. Ectopialentis. Surv Ophthalmol 1982; 27(3): 143-160.

6 Jensen AD, Cross HE, Paton D. Ocular complications in the Weill-Marchesani syndrome. Am J Ophthalmol 1974; 77(2): 261-269; 192.

7 Cruysberg JR, Boers GH, Trijbels JM, Deutman AF. Delay in diagnosis of homocystinuria: retrospective study of consecutive patients. BMJ 1996; 313(7064): 1037-1040. 